\title{
'Is Ethnicity the Root of all Evil?' Engaging Macro and Micro Analysis of Ethnic Violence in Post New-order Indonesia
}

Rizqy Amelia Zein Unversitas Airlangga, Indonesia

\begin{abstract}
In this theoretical review, the author examines intergroup conflicts and genocides in post NewOrder Indonesia as the manifestation of politicised nationalism by employing several theoretical approaches. The theoretical review starts from combining micro (social-psychological approach) and macro perspectives (sociological and political approach) to answer these following questions; (a) how do we explain intragroup conflicts and genocides, especially in post NewOrder Indonesia, as the consequences of nationalism's existence? (b) In what circumstances are intergroup conflict, or in the most extreme case; genocide, likely to occur? Thus, the theoretical review is structured into four parts; addressing the problem of intergroup conflict and genocide as well as emphasising its importance to be aware of; tracing back the emergence of the nation using Smith and Barthian's ethno-symbolic approach; narrating the conditions in which allow intergroup conflict arose; and some concluding remarks.
\end{abstract}

Keywords:

Ethnic Conflict; Ethnic Violence; Sociological Social Psychology; Post New-order Indonesia

\section{INTRODUCTION}

The number of ethnic conflicts that happened across the world, has been starting to deteriorate, especially since the twentieth of century (Mann, 2001). As revealed by Mann (2001, 2005), there were between 60 and 120 million people being murdered due to ethnic cleansing. This number is suddenly arising in the

Rizqy Amelia Zein s a lecturer and researcher at Faculty of Pshycology, Universitas Airlangga, Kampus B UNAIR, JI. Airlangga 4-6, Surabaya, Indonesia. Her research interests are community mental health, sociological aspects of mental health, the nexus between mental health and political participation and political activism in social media. (amelia.zein@psikologi.unair.ac.id). I am thankful for the insightful comments of the anonymous reviewers for this paper. $21^{\text {st }}$ century, not only because of the invention of bombing as an effective technique of annihilation, but also the idea of recognising the entire community as the enemy has become popular (Mann, 2001, 2005). Substantial killings, as Mann (2001) argued, is ubiquitous in almost the entire world; such as in several countries in the Middle East, Kosovo, Myanmar, Northern Ireland, India and many more.

Ethnic cleansing and genocide has been explored in innumerable researches with various theoretical perspectives in the past decades. Starting from some 
macro theories, Gellner (1983) argues that ethnic cleansing is mentioned as one of nationalizing strategies, in order to compel Gellner's formula; one nation for a single state (Hall, 2003). Additionally, this idea about homogenising the nation is somewhat came out caused by politicised ethnic nationalism (Varshney, 1993, 1998, 2003). Secondly, ethnic cleansing is also famously linked with "the dark side of democracy" (Mann, 2001, 2005). Several theorists assert ethnic conflict can also be happened as the logical consequence of social inequality and the misrecognition of "the other" (Hook, 2004; Taylor, 1994).

On the other hand, psychological studies about intergroup conflict have begun to catch genuine interest since Tajfel (1982) study about social identity and group identification became widely accepted. Furthermore, the psychological concept of social identity has been collapsed into several minor concepts, in order to investigate the essence of ethnic violence, such as in-group bias, in-group loyalty (Druckman, 1994) and infrahumanization of out-groups (Leyens, et.al., 2003). Both macro and micro perspective should not be divorced since they complement each other. Macro theories describe the conditions that enable ethnic conflict while micro theories deliver explanation why individuals can be voluntarily participated in mass violence (Finkel \& Straus, 2012).

This theoretical review was aimed to critically review ethnic conflict, which is often misguidedly seen that caused by ethnicity per se, using multi-layer theoretical approaches. By combining macro (sociological and political approach) and micro perspective (socialpsychological approach) and taking Indonesia as an exemplary case, I attempt to discuss these following key questions; (a) to what extent could ethnicity and nationalism be explained as the root of ethnic conflict or even genocide? (b) In what circumstances are intergroup conflict, or in the most extreme level; genocide, likely to occur?.

The paper is roughly fallen into three parts. The first part goes into the ethnosymbolic ideas about the role of ethnicity in creating a nation. This section is a first cut before putting ethnic conflict into the discourse. By understanding the relation between ethnic, nation, and nationalism; we need to clarify some key terms; such as ethnicity, nation, and nation state; before shifting to ethnic conflict issues. In the next section, we go through the conditions in which allow intergroup 
conflict is arisen and the further whether those categories are real or explanation about why individuals can be imagined (Varshney, 2003).

partaken in murderous ethnic cleansing at once. The last part summarises the entire ideas and offers some concluding remarks.

\section{Ethnicity, Nation, and Social Identity}

Ethnic community or ethnie, as described by Smith (2009: 27), is "a selfdefined human community whose member possess a myth of common ancestry, shared memories, one or more elements of common culture, including a link with a territory, and a measure of solidarity, at least among the upper strata". Moreover, (Özkirimli, 2005) argues that people would feel that they are related to each other only if they shared certain features, regardless of the obscurity in which and how many attributes are necessary to obtain this psychological bond. Ethnicity is used in two different modes (Varshney, 2003). Firstly, this simply refers to racial or linguistic groups. However, in a broader context, as Horowitz suggests, ethnicity can be interpreted as differentiation of groups on the basis of ascriptive or birthbased category such as religion, tribe, race, language, or even caste-regardless
A vital question began to arise; where does this consciousness of ethnic identity, which further grows into nationhood, come from? Fredrik Barth (Armstrong, 1994; Gellner, 1983) highlights that ethnic identities do not arise intrinsically within the group, but are emerged as the result of intergroup interaction. In other words, ethnic groups start to be aware of their uniqueness when they interact with other groups. This also implies that groups define themselves by comparing their characteristics with strangers (Armstrong, 1994).

Therefore, intergroup interaction between different ethnic groups creates boundaries between them and imposes them to preserve and to defend their ethnic identity (Gellner, 1983). Ethnic boundaries could also be seen as the rule of membership that distinguishes who is and is not a member of an ethnic group (Fearon \& Laitin, 2000). Moreover, ethnicity is defined by its boundaries rather than its content since the cultural content can be altered as time goes by while ethnic boundaries is simultaneously intact (Armstrong, 1994; Gellner, 1983). Furthermore, Smith (2009) provides slightly similar definition for the nation, 
but it requires supplementary elements, such as legal, territorial, and political dimension in which the ethnic community does not need to own. Essentially, ethnic group becomes nation once it is politicised. As Varshney (1993: 230) affirms, "A nation is not just a cultural community; rather, it is a sovereign cultural community." However, we should bear in mind that even ethno-symbolist believe that ethnicity has played an important role in shaping the nation; they do not deny that "other social and political processes are still required" (Smith, 2009).

Additionally, Smith (2009: 61) defines nationalism as "an ideological movement to attain and maintain autonomy, unity and identity on behalf of a population, some of whose members believe it to constitute an actual or potential nation". Hence, we can see that Smith (2009) stresses "ideological" and "identity" as key terms in defining nationalism. In this paper, I adopt (Varshney, 2003) idea that the terms of ethnicity and nation can be used interchangeably in order to avoid confusion

Then what motivates people to organise themselves on the basis of ethnicity? Smith (2009: 63) explains that there are key motifs that encourage people to develop nationalism. These motifs are included; providing individuals with autonomy, unity, identity, authenticity, the sense of belongingness of the homeland, dignity, consanguinity or continuity of kinship, and belief that such nation has a great destined future. Brewer, Manzi, \& Shaw (1993) and Crocker \& Luhtanen (1990) has demonstrated that membership in a certain social group is strongly associated with individual's self-esteem. At a nationlevel, groups provide individual's need of political power, sense of security, feeling of belonging and also status and prestige. The strength of these needs may vary in different nations and individuals, but these needs can be regarded as universal (Druckman, 1994).

\section{Is One State Solely Compatible for One Nation only?}

After discussing ethnicity as a vital building block to construct the nation in the earlier section, we are shifting to further complexity; namely the congruence between the nation and the state. As I mentioned earlier; ideally, one state only consists of only one nation. Because, as Gellner (1983: 134) points out, no one would be happy if they should 
"live in a state, or states, run by other and Nordholt, 2001; Weatherbee, 2002). alien cultural group."

Every policy was made in Jakarta and

A nation, as Gellner (1983) only tiny chances given to the lower-level describes, is a common membership in a authority to take part. The government shared high culture, which is a built military barracks or command units prerequisite for modernism and from the national to the village level. Army industrialism. The high culture actually was playing important role in keeping refers to a mass, rational, and scientificeveryone under constant surveillance to technological culture which is spread by a ensure that the regime's version of standardised language. Gellner (1983: 46)) also asserts "a modern industrialstate could only function if it has a literate, culturally homogenous, mobile, and interchangeable population." stability and security was delivered smoothly (Aspinall \& Berger, 2001; Elson, 2008; Weatherbee, 2002).

Discussing race, ethnicity, religion, Moreover, Gellner (1983: 1) defines and class (Suku, Agama, Ras, GolonganSARA) was a taboo and banned from the nationalism as "primarily a principle which holds that the political and national unit should be congruent". These all imply that Gellner (1983) stresses the unification of cultural elements as the fundamental process in order to shift the society from "Kokoschka to Modigliani".

This process was clearly apparent in Indonesia during the rule of Soeharto. During his regime, centralisation became widely expanded and structured uniformly in all regions. Championing the idea of melting pot policy, Soeharto was trying to eliminate ethnic, religious, cultural landscape boundaries for the sake of constructing the common characteristic of Indonesian people (Bertrand, 2004; public discourse (Nordholt, 2001; Schefold, 1998; Weatherbee, 2002). With an excessive anti-communism (Ekstrim Kiri-left extreme) and anti-radical Islam (Ekstrim Kanan-right extreme) propaganda until the very last of his presidency, Soeharto created imaginary enemies that peculiarly strengthened the bond between the people and helped Soeharto to control the nation with fear. With a very tight control and the stressing of internal stability, there were indeed only slight chances to oppose the government (Anderson, 2004; Brown, 2003; Elson, 2008; Mann, 2005). As an outcome, it was found that the relation between Indonesians' national and ethnic 
identity is consensual, which means those are socially-shared and harmoniously coexists (Zein, 2018).

Apparently, it is almost impossible to create such perfect congruent nation-state because in fact, only 12 from 132 states claimed themselves as a nation-state and the rest are multi-ethnic (Connor, 1994). Considering Conversi (2007) argument, "no society is, or has ever been, culturally homogenous" then it goes without saying that homogenising the whole part of the nation becomes necessary in order "to create the perfect fit between the nation and the state". Moreover, Hall (2003) insists that nationalism is meaningless without homogeneity and "homogeneity is what nationalism is about".

Hall (2003) draws a four-point continuum scale to describe the degree of cultural homogenisation; starting from voluntary assimilation practices to the most extreme level, a very nasty and vicious way, namely ethnic cleansing and genocide. Many thinkers believe that the dreadful point of Hall's (2003) continuum can be reached once the dominant ethnic group uses sovereignty as a vehicle to exclude the minority (Mann, 2001, 2005; Varshney, 2003). Likewise, Mann (2004: 3) has argued that, "nationalism is only dangerous when it is politicised" and often misrepresented as the modern look of aspiration, which is also prominently called democracy.

\section{Ethnic Conlict and the "Wicked" Side of Democracy}

Several liberal thinkers such as, John Stuart Mill, Robert Dahl and David Miller (1862, 1977, 1995 as cited in Hall, 2003) believe that politically stable democracy is able to achieve if cultural diversity had already been unified. Human beings cannot survive with too much conflict and even those theorists assert that "homogeneity is a necessity for generous welfare regimes" (Hall, 2003: 29). However, an excessive obsession with uniformity, homogenisation, shared origins is also proven as one of the important causes of the rise of fascism in many countries, such as Germany and Italy (Conversi, 1999). Moreover, when such multi-nation state has established a political order; the question regarding who is actually the legitimate holder of the state and who will regulate the distribution of public goods, began to arise (Mann, 2001).

The fundamental Mann's (2001: 3) argument, which bridges democracy with ethnic cleansing began with the deviation of the meaning of demos in democracy. 
Murderous ethnic cleansing is considered as a serious threat in the age of democracy when the idea of people twisted its meaning into "the dominant ethnos". This dominant ethnic group who rules the state is a Mann's (2001) first premise why the idea to label the whole member of the community as the enemy, thus justifies the annihilation of the whole people, is able to arise. Furthermore, Mann (2001) describes several essential conditions which enable the ethnic cleansing. I would only emphasise some of his key points in this theoretical review, but this does not mean the unmentioned arguments are less important.

The first condition that is essential is by looking at ethnic relation as a classic social process that has been drawn by socialist thinkers, namely the class struggle. Ethnic conflict emerges when ethnicity plays as the "main form of social stratification in the process of capturing and channelling class-like sentiments towards ethno-nationalism" (Mann, 2001: 4-5). Mann's (2001) argument seems in line with Gellner (1983: 121) who argues, "Only when a nation become a class, a visible an unequally distributed category in an otherwise mobile system, did it become politically conscious..." Gellner (1983: 121) also implies that conversely, a class, regardless how subordinated and exploited, will not be taken place in a political system otherwise "they define themselves ethnically". Hence, Mann (2001) and Gellner (1983) have made a point that inequality is the pivotal condition that ignites ethnic hostility.

Ethnic boundary is a crucial condition of ethnic conflict, but a mere segregation is not sufficient to entice friction. Ethnic conflict would not be able to arise until one ethnic group oppresses the other (Mann, 2004). Varshney (2003) asserts that the diversity per se is not the matter, but discrimination, inequality, and subordination raise the concern. Suppose that Apartheid does not involve racial exploitation, but merely ethnic segregation; then the minority groups would not have revolted (Mann, 2001; 2004).

By analysing the patterns of collective violence throughout the modern periods, Mann (2004) draws a conclusion that the struggle of political sovereignty is a pivotal cause of ethnic conflict, except in the colonial stage. In other words, ethnic boundaries and ideologies only matters once they start to ask who is supposed to rule the state. Economic-driven motifs are pervasive, but this is only limited to 
"economic gain obtained by possession of the state" (Mann, 2004: 235)

The second essential argument is ethnic cleansing cannot be exploded as an initial intent of the perpetrators. It is implausible that we can solely blame one person as a mastermind of a massmurder - even Hitler was not able to do that (Mann, 2001). Mann (2001) specifies three layers of the perpetrators, which should presence in condition of ethnic cleansing, namely elites, militants, and core constituencies. These three components interact in very complex way, generate substantial social movements. The power is expressed in three noticeable modes - "top-down by elites, bottom-up by popular pressure, and coercively sideways by paramilitaries" (Mann, 2001: 8).

Ethnicity as identity politics which was floated during Soeharto's era is starting to be more salient. Playing ethnic cards becomes one of politicians' favourite moves to gain influence. Disintegration issues also intensified and led to the birth of several armoured separatist movements, mostly in periphery areas (Mann, 2005).

Gerakan Aceh Merdeka (GAM-Free Aceh Movement) clashed with Indonesian Armed Forces and intensified and resulted almost 1.800 people died including civilians (Bertrand, 2004; Mann, 2005). Initially, people of Aceh only demanded special autonomy that allows them to retain their Islamic tradition. Ignored by Jakarta, the request was growing into a separatist movement. Thus, GAM's mission was to establish an independent Islamic state in Aceh (Aspinall \& Berger, 2001). Finally in 2005, GAM and Indonesia signed a peace agreement as the ending of a brutal armoured conflict which had been on-going since 1976 (Vickers, 2005).

Periphery areas, such as West Papua and East Timor, have been retaining a view that they do not have anything in common with the rest of the Republic since the day Soekarno declared Indonesia's independence. Papuans are Melanesian, mostly Christians and sharing a cultural closeness with the island of Papua New Guinea rather than Indonesia. No wonder that Papuans never completely embrace their existence as a part of Indonesia (King, 2002). Organisasi Papua Merdeka (Free Papua Movement-OPM) established in 1964 but started to intensify their confrontation with the Republic shortly after the regime's downfall. The armoured conflicts are still happening until now with over 20.000 
people have murdered in three decades, 1.500 in 2001 alone (Aspinall \& Berger, 2001; King, 2002; Mann, 2005).

The former Portuguese colony, a vast Christian and Portuguese-spoken community, East Timor, which was forced to join Indonesia in 1975, openly expressed their desire to be independent after suffering from a ruthless civil war for three decades during New Order era. The government had no option but sending troops and conducting military operations to retain its sovereignty in East Timor. Armoured conflict between Timorese and the Army resulted around 2000 people killed and 200.000 refugees (Mann, 2005). In 1999, sponsored by the UN, Indonesian government finally agreed to hold referendum and then led to the break-ups of East Timor with Indonesia in 2002 (Aspinall \& Berger, 2001).

Although other thinkers, such as (Conversi, 1999; Fearon \& Laitin, 2000) stress the role of elites in provoking ethnic conflict. The tyrant plays ethnic card as a strategy to maintain their legitimisation, to create obedience and to control internal dissent by creating the sense of threat and spreading fear (Conversi, 1999). Lesson learned from several ethnic conflicts in Indonesia that ironically followed a similar pattern with the Dutch colonial strategy, namely the implementation of politics devide-et-impera (Mann, 2001: 496). In West Papua, West Kalimantan and Moluccas, ethnic conflicts also put Indonesian ruling regime, which is represented by the Army, and the indigenous people on the same boxing ring. Indonesian government encouraged the presence of preman or local native bosses, offered them employment, contracts, and military backing. By provoking horizontal tense, the regime sought to cling to the power and to silence the dissenting voice by dividing and ruling the local ethnic groups (Mann, 2005; Varshney, Panggabean \& Tadjoeddin, 2004).

The last remark of Mann's (2001) formula of ethnic cleansing is the schema of bringing ordinary people in the frame of common social structures into committing ethnic cleansing. As this part is mainly played in micro level. It fits to the fact that sectarianism in Indonesia ever became a series of murderous ethnic conflicts, especially in West and Central Borneo, which involved Madurese and Dayaks. The local disputation turned out to be extremely dreadful as it led to the deaths of around 1000 people and hundreds thousands of Madurese were forced to flee (Bertrand, 2004; Mann, 2005). 
Meanwhile in Moluccas and Central Sulawesi, vicious conflicts involving Muslims and Christians made over 250 people killed and almost 70,000 left their homes (Mann, 2005). I offer to further discuss this matter by engaging it with some psychological issues in the forthcoming section.

The Politics of (mis)recognition and Neurosis of the Blackness

I attempt to elaborate the earlier exploration regarding inequality issues, by deepening the polarisation of superiorityinferiority dimension that comes up as another focal point, which ignites ethnic conflict. Charles Taylor's (1994) philosophical work may be a good start to clarify the relation between the needs of recognition with identity. Taylor starts his proposition by arguing that contemporary politics has become essentially shaped by the need of demand of recognition, which is requested by oppressed or subordinated individuals or groups (Martineau, Meer, \& Thompson, 2012; Özkirimli, 2005; Taylor, 1994). Taylor (1994) further argues that there are two changes that have been enabled the modern preoccupation with identity and recognition.
Firstly, the collapse of social stratification, which earlier constructed on the basis of honour, but now it has been replaced by dignity. The obvious impact by shifting honour to dignity is the demand aimed for democratic society to treat everyone equally. Therefore, "equal recognition is an essential part of democratic culture" (Özkirimli, 2005). Secondly, the emergence of the new conception of individualised identity, which Taylor (1994: 28) later named this concept as authenticity. This implies the importance of individuals of being true to themselves and suggests that moral calculation should not be interpreted as a mere "dry divine calculation of reward and punishment", but as an inner voice which came up from and anchored in our feelings.

The politics of recognition denotes two divergent demands. The shift from honour to dignity emphasise equal treatment, while the new conception of identity to respect the uniqueness of individuals or groups (Taylor, 1994; Özkirimli, 2005). The uniqueness has been ignored and assimilated to a dominant identity, thus it obviously represents the humiliation of authenticity (Özkirimli, 2005). Identity itself is believed by Taylor (1994) as dialogical 
and negotiated product that generates via interaction with the "significant others". Following Hegel's steps, Taylor (1994; Martineau, et.al., 2012) suggests that individual self-worth is deeply bounded to the label that others put to their cultural group. Thus, Taylor (1994: 36) asserts that equal recognition is not just obligatory condition of a healthy democratic society, even "its refusal (misrecognition/non-recognition) can inflict damage on those who are denied it. The projection of an inferior or demeaning image on another can actually distort and oppress, to the extent that the image is internalized". Misrecognition is not only the basis of oppression and subordination, but also enabled selfdepreciation-minorities are deeply internalised a picture of their own inferiority (Taylor, 1994).

A French psychoanalyst, Frantz Fanon details an extreme inferiority which is typically found in minorities, especially when he investigated the phenomenon of racism in the age of post-colonialism. Fanon (Hook, 2004) adopted Freudian psychoanalysis in emphasising the pathological condition of inferiority. Fanon (Hook, 2004: 115-116) argues that "the white coloniser and the black colonised exist within the grip of a massive psycho- existential complex' that has multiple detrimental psychological effects". This horrible effect is not only affected the dreams of the colonised, but also their psychic life, which makes them depicting their images as a white (Hook, 2004). However, unlike Freud's claim that the content of human psychic life is transhistorical, Fanon (Hook, 2004) proclaimed that the desire of being white is strictly bounded with a specific configuration of power, historical, cultural, and other socio-political dimensions of colonisation that continually encourage the white subject.

Fanon (Hook, 2004) conceptualised this desire as neurosis of blackness which constitutes "the wish to attain the level of humanity accorded to whites in racist/colonial context as it comes into conflict with one's being in a black body, and in a racist society, which makes this wish implausible". This form of neurosis is mainly caused by cultural trauma in which allow ambivalence feelings or strong emotional rejection towards the oppressor, but strangely coexist with contrary affective impulses. Basically, the deep hatred towards the oppressor exists alongside the desire of imitation (Hook, 2004). It is necessarily noted that this concept is not formulated as an individual 
phenomenon but rather as a social- emotion or bond, sympathy, and loyalty psychological phenomenon (Hook, towards their captors and often rationalise 2004). their captors' behaviour in order to make

This pattern is oddly apparent in postNew Order Indonesia. Romanticism it more tolerable (Adorjan, Christensen, seems to be an Indonesians' bad habit. Kelly, \& Pawluch, 2012; Namnyak, et.al., 2008). It comes out as a result of an Despite the achieved economic reliefs extreme fright or terror acts performed by after the great economic crisis in 1998, a the captors in order to make their victims survey finding extracted from a research helpless, completely submissive, and conducted by Indobarometer in 2011 revealed that most Indonesians were powerless.

missing their time being under the rule of Under such circumstances, any kind New Order regime and agreed that of slight kindness/goodness showed by Soeharto is the best Indonesian leader, despite his vicious style of leadership and numerous corruption cases plaguing himself and his circles. Historians believe that unity in Indonesia may only be delivered by practicing a melting pot and autocratic policy (Errington, 1999; the captors will lead the victim to perceive the criminals as "good guys" (Adorjan, et.al., 2012). Stockholm syndrome works at individual level, but Graham (1994) suggests that it also possibly work at wider societal level. In the case of Indonesia, the presence of the major Nordholt, 2001; Vickers, 2005). time (32 years) is sufficient to be the Furthermore, Mann (2005) pointed out that in Indonesia, the absence of authoritarianism is even more considered dangerous.

Indonesians who seems to be suffering from Stockholm syndrome are still far away from embedding collective guilt from past murders and conflicts. Stockholm syndrome is an intriguing psychological disorder whereby the basis of this argument; the symptoms of Stockholm syndrome in Indonesia are apparent. People are not completely regard Soeharto positively as a great hero, but the ambivalence of people's opinion towards him indicates the absence of collective guilt. The effect of this oddity is disturbing-the emergence of faulty mentality; "See No Evil, Hear No Evil, victims of crime develop peculiar positive 
On the contrary, a thought-provoking of a particular group) and in-group point made by Anderson (1999: 10-11) identification, leads to infra-humanisation in his article that he put forward a slogan or out-group hostility. A classic social "Long Live Shame" for Indonesia. No one psychological study conducted by Tajfel deserves to be called a nationalist when (1982) namely minimal-group paradigm, they are "incapable of feeling 'ashamed' if whereby people are differentiated on the their state/government commits crime," basis of trivial criterion under condition especially when the government slaughter free from other factors associated with they own citizens (Anderson, 1999: 10- group membership, is often adopted by 11). Although not everyone has been innumerable psychological studies to directly contributed in the catastrophe, as investigate the roots of ethnic conflict a member of an imagined community, (Druckman, 1994; Howard, 2000; everyone should feel morally discomfort in Leyens, et.al., 2003). This concept every bad thing happened in the name of constitutes even in this "minimal the nation. Anderson (1999) gives an condition, people do discriminate in example of Americans who were ashamed favour of in-groups in allocation of various of the fact that their government was rewards" (Howard, 2000: 369). involved in the killings of three million However, those explanations are not people in Indochina during Vietnam War. taking the broader social and political This political shame, according to context, into account. Thus, they are Anderson (1999) is always needed and insufficient to explain ethnic conflict, very good for the nationalism project. because those implicitly assume that the context of ethnic conflict is trans-historical

\section{Future Directions for Social Psychology}

Social psychology has attempted to grasp ethnic conflict by explaining outgroup hostility as a manifestation of ingroup loyalty (Druckman, 1994). In another study, Leyens, et.al. (2003) has demonstrated that nationalism, premediated by subjective essentialism (how people internalise the rule of membership or stable, which is obviously not.

Mann (2001) proposes that sociology of power is more needed to explain why common people can be involved in a mass-murder compared to a special perpetrator psychology. Strengthened by Collins (2009) who insists that "not violent individuals, but violent situations" that shapes one's emotions and acts that 
lead to violent behaviours. However, when it comes to individuality, these arguments are plausibly misguided. They comment as if the whole member of oppressive groups develops identical attitudes and actions. Not every German agrees with anti-Semitism, as (Wohlgelernter, 1997) reveals, “...there was a great deal of dissent and protest that we know about. So, this idea of blind German obedience is simply nonsense".

Sociology and politics would never been successful to narrate individual level of analysis regarding ethnic conflict without any help from psychological approach. The contribution of psychology in shaping ethnic conflict studies is therefore not supposed to be underrated in such level. By understanding ethnicity as one of in-group identification phenomenon, Tajfel (1982) points out that there are two layers of conditions which are prerequisites for group identification process. Firstly, a cognitive aspect in which people acquires the sense of membership; and evaluative aspect, in terms of how close the awareness of membership related to some value connotations (Tajfel, 1982). Let's devote our focus on the last layer-value connotation. What would happen if one perceives negatively their membership to a certain group? Are they still fancy to become the member or behave like one? Tajfel (1982) stresses that positive evaluative condition "is a necessary condition for the emergence of intergroup behaviour". In other words, there would be only a tiny chance that one voluntarily participates in mass-murder, if their personal value is opposed to the common belief.

Moreover, this also depends on to what extent they believe that their membership in a certain group as valuable (Druckman, 1994). Individuals "who saw the nation as a symbol for what was important in their life" tend to develop stronger affective attachment to their nation (Druckman, 1994: 45). Affective attachment determines how individual perceive their membership and how they develop attitudes and behaviours as the consequences of this membership. Therefore, it is clear that people treats "the stranger" differently depends on whether they view nationalism as important or not (Druckman, 1994), even if the nation instigates ethnic cleansing in order "to purify" their culture. 


\section{CONCLUSION}

Homogenisation is often linked to Gellner's (1983) formula- "one nation for one state". The idea of homogenising the whole nation for the sake of politically stable democracy is affirmed by innumerable thinkers (Hall, 2003). Additionally, ethnic conflict is more likely to happen when people starts to ask who is supposed to control the state (Mann, 2001, 2004). Hence, it is understandable that Mann $(2001,2004)$ blamed democracy for all these evil acts. Conversely, Taylor (1994) suggests that democracy is needed to make sure that people will be treated equally. Now we have seen the ambivalence of democracy. I prefer to support Mann's (2001, 2004) argument which affirms that politically stable democracy had to commit ethnic cleansing, in terms of institutionalised coercion rather than mass murder, in order "to produce an essentially monoethnic citizen body in the present" (Mann, 2004: 4).

Becoming aware of differences is insufficient condition to entice people for killing each other. It requires the presence of inequality and superior-inferior feelings in conflicted groups (Hook, 2004; Mann, 2001, 2005; Taylor, 1994; Varshney, 2003). The inequality condition is often conceptualised as ethnic-class struggle (Gellner, 1983; Mann, 2005), while superiority-inferiority is represented by misrecognition of others (Taylor, 1994) and the phenomenon of neurosis of blackness (Hook, 2004). Hence, it does not make sense when people just simply blame ethnicity as the root of ethnic conflict.

Social psychology has tried to investigate the cause of ethnic conflict by using group dynamics model; the results of those studies are inadequate and too simplistic as those did not account for the complex and typical social and political dimension. Conversely, sociological and political approach is unable to work when it raises a question regarding the involvement of individuals committing murderous ethnic cleansing as those did not account for individual differences which has been proven determining intergroup behaviour emergence. To sum up our discussion, we are not supposed to detach them as they complement each other.

\section{REFERENCES}

Adorjan, M., Christensen, T., Kelly, B., \& Pawluch, D. (2012). Stockholm Syndrome as Vernacular Resources. 
The Sociological Quarterly, 53(178), 454-474.

Anderson, B. (1999). Indonesian nationalism today and in the future. Indonesia, 67(67), 1-11.

Anderson, B. (2004). The Future of Indonesia. In M. Seymour (Ed.), The Fate of The Nation State (pp. 375389). Montreal: McGill University Press.

Armstrong, J. (1994). Nations before nationalism. In J. Hutchinson \& A. D. Smith (Eds.), Nationalism (pp. 140147). Oxford: Oxford University Press.

Aspinall, E., \& Berger, M. T. (2001). The break-up of Indonesia? Nationalisms after decolonisation and the limits of the nation-state in post-cold war Southeast Asia. Third World Quarterly, 22(6), 1003-1024.

Bertrand, J. (2004). Nationalism and Ethnic Conflict in Indonesia. Cambridge: Cambridge University Press.

Brewer, M. B., Manzi, J. M., \& Shaw, J. S. (1993). In-group identification as a function of depersonalization, distinctiveness, and status. Psychological Science, 4(2), 88-92.
Brown, C. (2003). A short history of Indonesia: The unlikely nation? Maryborough: Allen \& Unwin.

Collins, R. (2009). Violence: A Microsociological Theory. New Jersey: Princeton University Press.

Connor, W. (1994). A nation is a nation, is a state, is an etnic group, is a... In J. Hutchinson \& A. D. Smith (Eds.), Nationalism (pp. 147-154). Oxford: Oxford University Press.

Conversi, D. (1999). Nationalism, boundaries, and violence. Millennium, 28(3), 553-584.

Conversi, D. (2007). Homogenisation, nationalism and war: should we still read Ernest Gellner?*. Nations and Nationalism, 13(3), 371-394.

Crocker, J., \& Luhtanen, R. (1990). Collective self-esteem and ingroup bias. Journal of Personality and Social Psychology, 58(1), 60-67.

Druckman, D. (1994). Nationalism, patriotism, and group loyalty: A social psychological perspective. Mershon International Studies Review, 38(1), 43.

Elson, R. E. (2008). The Idea of Indonesia: A history. New York: Cambridge University Press. 
Errington, J. (1999). Language, religion, and identity in Indonesia. ISIM Newsletter, 9. Retrieved from

Fearon, J. D., \& Laitin, D. D. (2000).

Violence and the social construction of ethnic identity. International Organization, 54(4), 845-877.

Finkel, E., \& Straus, S. (2012). Macro, meso, and micro research on genocide: Gains, shortcomings, and future areas of inquiry. Genocide Studies and Prevention, 7(1), 56-67.

Gellner, E. (1983). Nations and Nationalism. New York: Cornell University Press.

Graham, D. L. R. (1994). Loving to Survive: Sexual Terror, Men's Violence, and Women's Lives. New York: NYU Press.

Hall, J. A. (2003). Condition for national homogenizers. In U. Ozkirimli (Ed.), Nationalism and Its Future (pp. 1531). London: Palgrave Macmillan.

Hook, D. (2004). Fanon and the psychoanalysis of racism. In D. Hook (Ed.), Critical Psychology (pp. 114137). Landsdowne: Juta Academic Publishing.

Howard, J. A. (2000). Social psychology of identities. Annual Review of Sociology, 26, 367-393.
King, P. (2002). Morning star rising? Indonesia Raya and the new Papuan nationalism. Indonesia, 73(73), 89127.

Leyens, J.-P., Cortes, B., Demoulin, S., Dovidio, J. F., Fiske, S. T., Gaunt, R., Vaes, J. (2003). Emotional prejudice, essentialism, and nationalism The 2002 Tajfel lecture. European Journal of Social Psychology, 33(6), 703717.

Mann, M. (2001). Explaining murderous ethnic cleansing: The macro level. In M. Guibernau \& J. Hutchinson (Eds.), Understanding Nationalism (pp. 207-241). Oxford: Polity Press.

Mann, M. (2005). The Dark Side of Democracy: Explaining ethnic cleansing. Cambridge: Cambridge University Press.

Martineau, W., Meer, N., \& Thompson, S. (2012). Theory and practice in the politics of recognition and misrecognition. Res Publica, 18(1), 1-9.

Namnyak, M., Tufton, N., Szekely, R., Toal, M., Worboys, S., \& Sampson, E. L. (2008). "Stockholm syndrome": psychiatric diagnosis or urban myth? Acta Psychiatrica Scandinavica, 117(1), 4-11. 
Nordholt, N. (2001). Indonesia, a nationstate in search of identity and structure. Bijdragen Tot de Taal-, Land-En Volkenkunde, 157, 881901.

Özkirimli, U. (2005). Contemporary Debates on Nationalism: A Critical Engagement. Palgrave Macmillan.

Schefold, R. (1998). The domestication of culture: Nation-building and ethnic diversity in Indonesia. Bijdragen Tot de Taal-, Land-En Volkenkunde, 154, 259-280.

Smith, A. D. (2009). Ethno-Symbolism and Nationalism: A Cultural Approach. London: Taylor \& Francis.

Taylor, C. (1994). The politics of recognition. In A. Gutmann (Ed.), Multiculturalism: Examining the politics of recognition (pp. 25-73). New Jersey: Princeton University Press.

Varshney, A. (1993). Contested meanings: India's national identity, Hindu nationalism, and the politics of anxiety. Daedalus, 122(3), 227261.

Varshney, A. (1998). Why democracy survives. Journal of Democracy, 9(3), 36-50.
Varshney, A. (2003). Nationalism, ethnic conflict, and rationality. Perspective on Politics, 1(01), 85-99.

Varshney, A., Panggabean, R., \& Tadjoeddin, M. Z. (2004). Patterns of Collective Violence in Indonesia (1990-2003). Jakarta.

Vickers, A. (2005). A history of modern Indonesia. New York: Cambridge University Press.

Weatherbee, D. (2002). Indonesia: Political Drift and State Decay. The Brown Journal of World Affairs, IX(1), 23-33.

Wohlgelernter, M. (1997). Hitler's willing executioners. Society, 34(2), 32-37.

Zein, R. A. (2018). What's the matter with being Indonesian? A social representation approach to unravelling Indonesian national identity / ¿Qué significa ser indonesio? Una perspectiva de la representación social para desentrañar la identidad nacional Indonesia. Revista de Psicologia Social, 33(2), 390-423. 